\title{
PRÁTICAS PRODUTIVAS DA FARINHA DE MANDIOCA NA COMUNIDADE QUILOMBOLA MOCAMBO - OURÉM - PA
}

\author{
Josiane Santos da Silva ${ }^{1}$ \\ Lene da Silva Andrade ${ }^{2}$ \\ Andrey Mendonça de Souza ${ }^{3}$ \\ Fabio Halmenschlager ${ }^{4}$
}

\begin{abstract}
RESUMO
O Mocambo, em Ourém, Estado do Pará é uma comunidade quilombola que possui a agricultura como uma das principais atividades econômicas. Produz a farinha de mandioca como destaque, essencial para reprodução social, cultural e econômica da comunidade. Este artigo investiga quais fatores influenciaram as possíveis mudanças nas práticas produtivas da mandioca na comunidade do Mocambo. É uma pesquisa qualitativa, onde foram entrevistados oito agricultores, respondendo a um questionário. Os resultados mostraram que grande parte dos entrevistados frequentou apenas até a quarta série do ensino fundamental. A média de idade é de 55 anos, sendo moradores locais há pelo menos 46 anos. A mandioca produzida é plantada na roça, cujo tamanho varia entre 2 e 6 tarefas. A comercialização é feita esporadicamente e/ou quando há excesso de produção ou necessidade econômica. O Mocambo sofre forte influência de aspectos mercadológicos, novas tecnologias e a falta de sucessores no âmbito da produção de farinha de mandioca. O itinerário técnico indicou algumas mudanças na produção que podem ser explicados seja pela proximidade com as indústrias de farinha, por facilidade de acesso às informações, acesso à energia elétrica, ou simplesmente por incorporação às novas tecnologias. Apesar da pressão de mudanças, ainda conseguem produzir combinando costumes e saberes intergeracionais as novas tecnologias.
\end{abstract}

Palavras-chave: Quilombo. Farinha de mandioca. Saberes locais.

\section{PRODUCTIVE PRACTICES OF CASSAVA FLOUR IN THE QUILOMBOLA COMMUNITY MOCAMBO - OURÉM - PA}

\begin{abstract}
Mocambo, in Ourém, State of Pará, is a quilombola community that has agriculture as one of its main economic activities. It produces cassava flour as a highlight, essential for social, cultural and economic reproduction of the community. This paper investigates what factors have influenced possible changes in the productive practices of cassava in the community of Mocambo. It is a qualitative research, where eight farmers were interviewed, answering a questionnaire. The results showed that a large part of the interviewees had only attended up to the fourth grade of elementary school. The average age is 55, and they have been local residents for at least 46 years. The cassava produced is planted in the field, whose size varies between 2 and 6 tasks. The commercialization is done sporadically and/or when there is excess production or economic need. Mocambo is strongly influenced by market aspects, new technologies, and the lack of successors in cassava flour production. The technical itinerary indicated some changes in production that can be explained either by proximity to the flour industries, ease of

1 Doutoranda do Programa de Pós-Graduação em Desenvolvimento Sustentável do Trópico Úmido (PPGDSTU/NAEA) pela Universidade Federal do Pará (UFPA). ORCID: https://orcid.org/0000-0001-54362419.E-mail: agricultura.j.s@gmail.com.

2 Mestranda em Diversidade Sociocultural (PPGDS) do Museu Paraense Emílio Goeldi (MPEG). ORCID: https://orcid.org/0000-0002-4982-759X. E-mail: lene.s.andrade2@gmail.com.

3 Mestrando em Agriculturas Familiares (PPGAA) pela Universidade Federal do Pará (UFPA). ORCID: https://orcid.org/0000-0002-5960-8390. E-mail: andreyourem@gmail.com.

${ }^{4}$ Doutor em Antropologia pela Universidade Federal Fluminense, professor da Universidade Federal do Pará, lotado no Instituto Amazônico de Agriculturas Familiares. ORCID: https://orcid.org/0000-0003-3811-0654. Email: fabiohalmenschlager@gmail.com.
\end{abstract}


access to information, access to electricity, or simply by incorporation of new technologies. Despite the pressure for change, they still manage to produce by combining customs and intergenerational knowledge with new technologies.

Keywords: Quilombo. Cassava flour. Local knowledge.

Data de submissão: 02.08 .2021

Data de aprovação: 01.12 .2021

\section{INTRODUÇÃO}

[...] Acordam! É hora de ir para o roçado Vão encher a cabaça de água Amolam a foice e o terçado.

As casas eram feitas de palhas As portas feitas de parí Quando arribava de casa Carregavam na costa o jamaci E varriam suas casas Com vassouras de botão ou vassouras de açaí.

Depois de um dia de trabalho A noite acendiam o lampião Reuniam a família

E juntos debulhavam feijão Era uma pequena atividade Que servia como distração $[\ldots]^{5}$

No pequeno trecho reproduzido acima, é possível observar a trajetória de vida dos habitantes pobres da comunidade do Mocambo, onde a principal atividade desenvolvida é a agricultura, aqui representada através do roçado. Os residentes mais antigos relembram as dificuldades de moradias na época de seus antepassados. A maioria morava em casas construídas de barro, com telhado feito de palhas de açaí, ou cavacos (madeira) que na época de inverno, devido às fortes chuvas, eram insuficientes para protegê-los, resultado da fragilidade do material.

Tinham dificuldade de acesso às escolas, já que localizavam- se a $3 \mathrm{~km}$ da cidade de Ourém. Naquela época, as crianças revezavam entre os estudos e o trabalho na roça com intuito de contribuir nas atividades praticadas em família, dentre elas, a principal era a preparação da farinha de mandioca. Ainda muito exercida na região, segundo relatos dos entrevistados.

A partir deste contexto, esta pesquisa teve como objetivo principal investigar, a partir da narrativa dos agricultores e agricultoras do Quilombo do Mocambo, quais fatores influenciaram as possíveis mudanças nas práticas produtivas da mandioca. Como objetivos específicos o trabalho caracterizou o perfil socioeconômico dos produtores de mandioca, identificou as variedades utilizada na comunidade, descreveu o modo e as ferramentas com os quais os agricultores produziam e produzem a farinha de mandioca, e finalmente identificou as possíveis mudanças nas práticas e/ou ferramentas envolvidas no processo produtivo da farinha.

Foram entrevistados oito agricultores, portanto, esta pesquisa tem um direcionamento qualitativo. Partindo do pressuposto de que fatores de mercado, novas tecnologia e idade dos produtores influenciaram as mudanças na produção da farinha de mandioca no Mocambo, a pesquisa se desenvolveu em torno da seguinte pergunta: Quais fatores foram responsáveis pelas

\footnotetext{
${ }^{5}$ (Trecho de "Rimas de cordel recordar é viver", escrito por Maria Madalena R. Souza, quilombola da comunidade
} do Mocambo). 
possíveis mudanças nas estratégias de produção da farinha de mandioca, no quilombo do Mocambo, Ourém, Estado do Pará?

Assim, a escolha por estudar este tema surgiu a partir do momento em que se observou a importância em (re)conhecer, valorizar e preservar as práticas produtivas da farinha de mandioca no Mocambo, conforme desejo dos próprios agricultores que estão empenhados em resgatar as raízes de sua tradição, seja pelo viés das artes, dança e música, ou através das atividades econômicas e/ou sociais, caso da farinha de mandioca. Na comunidade em questão a produção de farinha se desenvolveu ao longo do tempo, e, por ser um dos principais alimentos integrantes da dieta local, torna-se importante para a segurança e soberania alimentar da comunidade e, por extensão, promove a manutenção das relações históricas e socioeconômicas.

As informações adquiridas nesta pesquisa podem contribuir na perspectiva de demonstrar que o agricultor quilombola reconhece a importância da continuidade dos modos tradicionais de produção, e ao mesmo tempo, incorpora novas técnicas produtivas ao processo de produção da farinha, em que uma não exclui a outra. Acrescenta-se a importância das comunidades tradicionais, e neste caso, quilombolas, frente ao seu papel histórico na construção da sociedade brasileira, como mostraram os pesquisadores José Jorge de Carvalho, Abdias do Nascimento, Beatriz do Nascimento e Clóvis Moura, dentre outros.

O texto apresentado está dividido em cinco partes. A primeira é uma introdução sobre a comunidade do Mocambo e a motivação para iniciar a pesquisa. Na segunda parte, disponho do referencial teórico que contribui para uma reflexão a respeito das comunidades quilombolas e a relação das comunidades tradicionais com a mandioca. Em seguida são descritos o material e métodos utilizados na pesquisa, com objetivo de indicar o caminho percorrido para as análises e conclusão. Na quarta parte, inicia a discussão dos resultados encontrados na pesquisa e finalmente é apresentado as considerações finais das experiências na comunidade.

\section{COMUNIDADES QUILOMBOLAS}

Os quilombos foram e são espaços de resistência, ante a escravidão ao longo da história do Brasil (DA SILVA, DA SILVA, 2015). O país é o segundo maior em ascendência Africana, e segundo Anjos (2014), o número de "importação forçada de africanos" ao longo dos séculos XVI e XIX foi maior que quatro milhões de pessoas. Esta violenta e cruel retirada de pessoas de seu ambiente natural, e de sua cultura teve como objetivo sua incorporação "às tarefas básicas para formação de uma nova realidade" (ANJOS, 2011, p. 262) que segundo o mesmo autor foi a base para a construção da sociedade racista que hoje conhecemos (ANJOS; CYPRIANO, 2006, p. 25).

A escravização do negro se tornou efetiva e lucrativa devido a vários fatores. Os africanos tinham habilidades com sua mão de obra que os tornavam mais atraentes, com capacidades na agricultura, na mineração, na construção, como ferreiros, e tinham um baixo custo para os colonizadores (DA SILVA, DA SILVA, 2015). Assim, a mão de obra escrava africana era bem comum em diversas tarefas, desde serviços domésticos, até a construção de pontes e estradas.

Apesar do trabalho forçado, dos castigos e punições, os africanos tiveram como característica marcante a resistência à escravidão (FUNARI, 1996). Assim, segundo Reis e Dos Santos Gomes:

Onde houve escravidão houve resistência. E de vários tipos. Mesmo sob a ameaça do chicote, o escravo negociava espaços de autonomia com os senhores ou fazia corpo mole no trabalho, quebrava ferramentas, incendiava plantação, agredia senhores e feitores, rebelava-se individual ou coletivamente. Houve, no entanto, um tipo de resistência que poderíamos caracterizar como a mais típica da escravidão e de outras formas de trabalho forçado. Trata-se da fuga e formação de grupos de escravos 
fugidos. A fuga nem sempre levava a formação desses grupos. Ela podia ser individual ou até grupal, mas os escravos terminavam procurando se diluir no anonimato da massa escrava e de negros livres (REIS; DOS SANTOS GOMES, 1996, p. 9).

Os autores mostram que houve vários tipos de resistência, coletiva ou individual, onde diversas vezes formavam os "quilombos" locais para recomeçar a vida. O termo "quilombo" é de origem banto $^{6}$ e significa acampamento ou fortaleza e foi muito utilizado pelos portugueses com objetivo de reconhecer povoados construídos por escravos fugitivos. Os moradores dos quilombos, mocambos ou arranchamentos eram chamados pelos nomes de Callombolas, Quilombolas ou Mocambeiros (DA SILVA, DA SILVA, 2015).

Para Ramos (1996), não existia homogeneidade nos quilombos, podendo variar sua localização, dimensão, população, configuração organizacional e integrantes. O destaque do autor é para importância destas comunidades, onde "desempenharam um importante papel no complexo tecido social que era o sistema brasileiro da escravidão" (RAMOS, 1996, p. 165). Assim, é importante compartilhar a divergência existente entre os conceitos a respeito dos quilombos, Arruti (2008) faz uma reflexão:

Não é possível falar deles sem adjetivá-los. Seja por meio da fórmula legal que lança mão de "remanescentes", ou das tentativas de ajuste desta, por meio de "contemporâneos". Seja ainda porque são necessárias distinções entre estes, quando se usa "urbanos" ou "rurais". Ou, quando se quer tipificá-los, por meio de "agrícola", "extrativista", "nômade" etc. Ou, finalmente, quando se fala em "históricos", de forma complementar ou concorrente àquelas formas anteriores, já que falar em "quilombos históricos" tem servido tanto para especificar quanto para deslegitimar os "quilombos contemporâneos" (ARRUTI, 2008, p. 102).

Em meio às várias lutas em prol da interpretação mais realística do que sejam "quilombolas", nesta pesquisa será utilizado o conceito apresentado no decreto 4.887 , de novembro de 2003, o qual foi baseado para deliberar o título a comunidade em estudo, que em seu artigo $2^{\circ}$ considera:

Remanescentes das comunidades dos quilombos os grupos étnico-raciais, segundo critérios de auto atribuição, com trajetória histórica própria, dotados de relações territoriais específicas, com presunção de ancestralidade negra relacionada com a resistência à opressão histórica sofrida.

Parágrafo $1^{\circ}$. Para os fins deste Decreto, a caracterização dos remanescentes das comunidades dos quilombos será atestada mediante auto definição da própria comunidade.

Parágrafo $2^{\circ}$. São terras ocupadas por remanescentes das comunidades dos quilombos as utilizadas para a garantia de sua reprodução física, social e cultural (BRASIL, 2003).

Segundo informações da Fundação Cultural Palmares, até junho de 2021, ela havia emitido 2.819 declarações para comunidades quilombolas, destas $61,9 \%$ estavam localizadas no Nordeste, e somente $10 \%$ no Norte do país. Os dados indicaram 2006 como o ano que mais se gerou certificações (393), enquanto o ano de 2021 apresentou o menor número de comunidades certificadas (somente 19) desde 2004, período que se iniciou o processo de legitimação. Para estas comunidades a chancela política e social destas certidões projeta e imprime mais visibilidade ao seu contexto histórico de comunidade tradicional.

\footnotetext{
${ }^{6}$ Banto é um termo originário de idiomas da África central e austral, como acontece com o umbundo, quimbundo, bakongo etc. [...] A palavra bantu é linguístico dos africanos de Angola, Congo, Moçambique e adjacência, só foi cunhado no século XIX, concentrando-se na região sudeste, mas espalhados por toda parte (VAINFAS, 2000, p. $66)$.
} 
No Brasil, as comunidades tradicionais, ou populações tradicionais, tiverem sua definição articulada a partir dos debates sobre a criação das unidades de conservação (UCs), sendo aquelas afetadas pelos impactos de grandes projetos, disputas por territórios, grilagem de terra e outras situações que exigiam do poder público a inserção destas comunidades em políticas públicas de proteção, ou garantia dos seus direitos. Para o Decreto $n^{\circ} 6.040$ de 7 de fevereiro de 2007:

\footnotetext{
Art. $3^{\circ}$, I - Povos e Comunidades Tradicionais: grupos culturalmente diferenciados e que se reconhecem como tais, que possuem formas próprias de organização social, que ocupam e usam territórios e recursos naturais como condição para sua reprodução cultural, social, religiosa, ancestral e econômica, utilizando conhecimentos, inovações e práticas gerados e transmitidos pela tradição (BRASIL, 2007).
}

Segundo Santos (2008), as comunidades tradicionais cotidianamente desenvolveram uma vivência harmoniosa com a natureza, pois acreditavam fazer parte dela, de onde coletavam, caçavam, pescavam, manipulavam as propriedades farmacêuticas das plantas e ervas, domesticavam espécies de plantas e plantavam para sua alimentação. Utilizavam formas de desfrutar a natureza sem agredi-la, de forma sustentável. Essa maneira de coexistir com o mundo natural foi passada de pais para filhos(as) de forma oral durante o convívio diário (PASA; ÁVILA, 2010).

Igualmente, a ação de plantar para alimentação trazendo modos particulares de produzir será objeto de estudo desta pesquisa. A mandioca é um exemplo de alimento muito utilizado por populações e comunidades tradicionais, como será visto ao longo do próximo tópico.

\section{MANDIOCA: HISTÓRIA E PRODUÇÃO}

A mandioca (Manihot esculenta Crantz) já era cultivada por populações indígenas muito antes da chegada dos colonizadores europeus no continente americano, por volta do século XV. Originária, possivelmente do Brasil Central, a raiz era tida como base da alimentação destes povos (ALLEM, 2002; FRASER E CLEMENT, 2008; SCHAAL et al; 2006; PIPERNO, 2011). Nos Estados do Pará e Amazonas foi observado que, ao lado dos indígenas, havia também descendentes de escravos que cultivavam a mandioca como parte de sua cultura, realizando a festa da colheita, a "farinhada" (AGUIAR, 1982). Nos dias atuais, a mandioca é o produto mais consumido no mundo e no Brasil por todas as camadas da população, sendo importante fonte de carboidrato (amido) segundo dados da Companhia Nacional de Abastecimento (2017).

A Organização das Nações Unidas para a Alimentação e Agricultura (FAO) mostra em números a importância mundial da mandioca que chegou ao número de 277,9 milhões de toneladas no ano de 2017. Os maiores produtores mundiais estão concentrados em três continentes diferentes: A África representada pela Nigéria, principal produtor com 55 milhões de toneladas, seguido pelo continente Asiático (Tailândia com 30,9 milhões de t, e Indonésia produzindo 20,3 milhões de t, segundo e terceiro lugar, respectivamente), enquanto o Brasil é o quarto produtor mundial apresentando 20,1 milhões de toneladas de mandioca. Apesar do volume produzido, a FAO indicou queda na produção mundial e regional entre os anos de 2017 e 2018. No Brasil a seca causou diminuição do plantio resultando em um declínio de $15 \%$ na safra.

Dentre os Estados brasileiros, o Pará é o maior produtor de mandioca com 4,19 milhões de toneladas segundo dados da CONAB (2017), movimentando em torno de R $\$ 1$ bilhão por ano (IBGE). O Estado seguiu as previsões da FAO tendo área colhida reduzida de 294,337 hectares (2017) para 265.578 hectares (2018). Apesar da redução, a cadeia produtiva da mandioca gera empregos desde o início da produção, que se dá no campo, até a fase de processamento e comercialização, gerando aproximadamente um milhão de empregos diretos 
(EMBRAPA, 2017). Portanto, a mandioca é importante para o Estado do Pará, não somente para o viés comercial, mas também sociocultural, pois se faz presente na história de comunidades camponesas tradicionais espalhadas por todo o Brasil, geralmente consumida principalmente em forma de farinha.

No Estado do Pará, o meio rural é desenvolvido também em torno da produção da farinha de mandioca. Por possuir características de alta adaptabilidade, mesmo em condições desfavoráveis (solo, clima, variedade), a mandioca se desenvolve bem em solos regionais sendo importante geradora de emprego e renda, principalmente para pequenos e médios produtores. Outra característica da planta é seu aproveitamento total, pois dela pode-se utilizar todas as partes, desde o caule, a raiz e até as folhas (LOBO; DOS SANTOS JÚNIOR; NUNES, 2018).

Sendo intensamente utilizada na culinária amazônica, onde é base para o preparo de pratos cotidianos ou refinados, se destacando por fazer parte na construção da identidade regional. Da raiz faz-se a farinha d'água, farinha de tapioca, farinha temperada, beiju, carimã ou massa puba, o tucupi e a goma utilizados no tacacá paraense. As folhas são moídas e cozidas por sete dias, sendo acrescido da carne de porco salgada, dando origem a Maniçoba, prato típico da comida local.

Logo é notável a relação de proximidade entre a mandioca e as populações tradicionais da região, pois desta relação hoje se tem uma variedade de modos de consumir e produzir a planta. Mas, apesar dessa forte afinidade, o estudo realizado por Santana (2018) mostra as influências pela qual as comunidades têm passado, para a autora, "as famílias que praticam as farinhadas, atualmente passam por um processo de subalternização do saber fazer por meio de instituições como a Embrapa" (SANTANA, 2018, p. 34).

Esta instituição propõe padrões que desafiam a lógica de vida dos agricultores tradicionais, pois estas consideram a farinha como um produto exclusivamente de comercialização, enquanto os agricultores entendem a farinha como o pão para consumo diário. Estando exatamente nesta diferença de perspectiva, entre agricultor quilombola, caso desta investigação, e os estabelecimentos de pesquisa, a divergência fundamental que precisamos entender e por vezes desestimular.

De tal modo, como ocorreu na comunidade do Mocambo, município de Ourém, Estado do Pará, foco desta pesquisa. Na localidade, as relações de produção da farinha de mandioca podem ter sofrido influências de atores externos, e por isso justifica-se esta pesquisa com objetivo de retratar esse cenário.

\section{MATERIAL E MÉTODOS}

\section{1 ÁREA DE ESTUDO}

Dentro do município de Ourém, está situada a comunidade remanescente de quilombola Mocambo (Figura 1). A comunidade fica distante $3 \mathrm{~km}$ da sede de Ourém, à margem direita do Rio Guamá e foi reconhecida oficialmente como remanescente de quilombola em 2012 pelo Instituto de Terras do Pará (ITERPA). Mocambo está localizada na Zona rural do município de Ourém, Estado do Pará e possui uma área total de 657 há, onde moram aproximadamente 147 famílias (IBGE; Secretária municipal de Saúde de Ourém). 
Figura 1- Mapa de localização da comunidade do Mocambo, município de Ourém, Estado do Pará

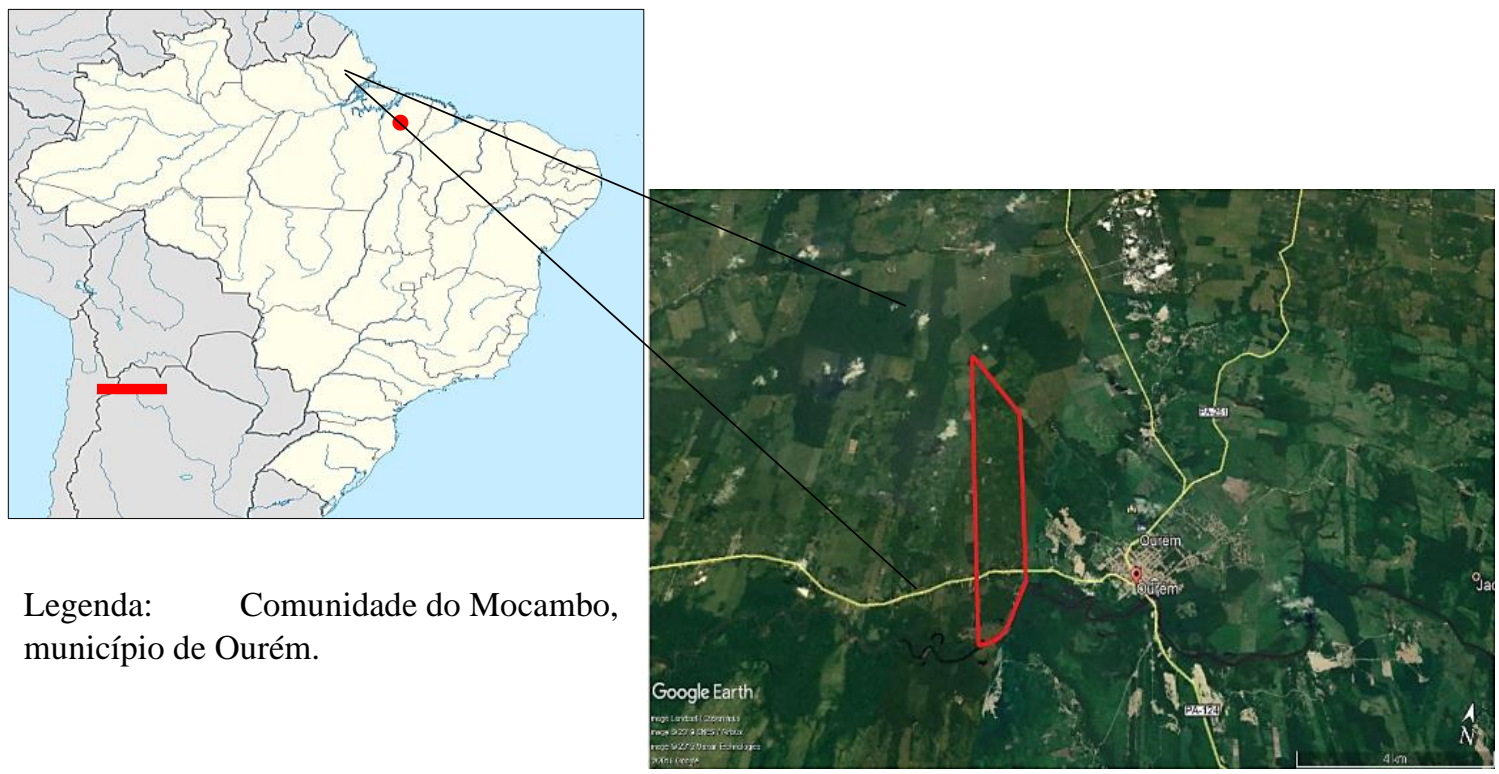

Fonte: Adaptado pela autora do Google Earth, 2019.

A fundação do Mocambo, como hoje é conhecido, será retratada aqui por meio de narrativas dos moradores da localidade e de alguns trabalhos feitos na comunidade pelos próprios quilombolas que tiveram a possibilidade de cursar uma graduação. A comprovação do histórico da comunidade se deu através de relatos orais e a presença de um engenho de açúcar movido a tração animal.

A comunidade foi fundada por avós e bisavós dos atuais moradores, que eram pessoas negras escravizados por volta de 1830. Estas pessoas, em busca de sua liberdade, fugiam através do Rio Guamá utilizando os pequenos vilarejos (Tuntum, Japirica, São João, João Pereira e Menino Jesus) como esconderijo. Este pequeno aglomerado de casas futuramente iria se unir e formar a Comunidade Quilombola do Mocambo.

\subsection{PROCEDIMENTOS METODOLÓGICOS}

Esta pesquisa é um estudo onde procurou compreender as circunstâncias e a conjuntura local, através dos sentidos e emoções dos sujeitos envolvidos, desta forma, os entrevistados são os produtores de conhecimentos e práticas (CHIZZOTTI, 1991). Portanto, esta é uma pesquisa qualitativa onde se observa o elemento em seu estado natural (ANDRÉ, 2005).

\subsubsection{PRÉ-TESTE}

Esta técnica foi utilizada com objetivo de testar o efeito do questionário, e da abordagem da entrevista, além de iniciar uma sondagem com a comunidade. Assim, tendo proximidade junto aos informantes-chave e na oportunidade esclarecer a pesquisa de forma mais tranquila e se necessário, ajustar a metodologia.

\subsubsection{OBSERVAÇÃO DIRETA}

Por meio da observação direta e da entrevista fez-se a transcrição de algumas atividades cotidianas dos entrevistados. 


\subsubsection{ENTREVISTA SEMIESTRUTURADA}

Esta pesquisa é um estudo de caso, na qual utilizou-se o questionário, contendo perguntas abertas e fechadas. As entrevistas ocorreram de outubro a dezembro de 2019, no período matutino e vespertino adequando-se ao tempo disponível dos entrevistados.

A condução das entrevistas foi inspirada na pesquisa de Santana (2018), que a entende como "a ação de se pôr a ouvir e traduzir para os de fora e, se necessário, apresentar para os de dentro o quão importante é o registro dos saberes e fazeres tradicionais". Portanto, os pilares que sustentam essa pesquisa são o de registro e o da interpretação.

\subsubsection{DIÁRIO DE CAMPO}

Este instrumento segundo Magnani (1997) é fundamental em pesquisas observatórias, sendo indispensável para a pesquisa, e utilizado como depositário de notas, impressões, observações, primeiras teorizações, mapas, esboços, desabafos e entrevistas. Foi utilizado gravador de áudio e máquina fotográfica para registrar todos os detalhes.

\subsubsection{ESCOLHA DA AMOSTRAGEM}

Durante o andamento da pesquisa e após a realização do pré-teste notou-se a necessidade de ouvir os agricultores mais envolvidos na produção da mandioca. Tanto os mais velhos, quanto os mais novos, homens e mulheres. Também foi importante entrevistar aqueles que moravam ao centro da comunidade, ou seja, próximo as casas de farinha industriais, assim como aqueles que viviam distantes destes dois centros, e estavam localizados à beira do Rio Guamá.

O universo da pesquisa foi constituído por moradores da comunidade do Mocambo. As entrevistas foram concedidas nas casas e roças dos agricultores, onde se percebeu maior disponibilidade de abertura. Antes de iniciar a pesquisa explicou-se o seu objetivo, assim como foi apresentado o Termo de Consentimento Livre e Esclarecido (TCLE). Foram entrevistados oito agricultores, sendo quatro mulheres e quatro homens. Ao longo do texto será utilizada fala direta apenas de quatro produtores, identificados como interlocutores: A, B, C e D. Dessa forma terão suas identidades preservadas.

Os dados coletados foram organizados com ajuda do software da Microsoft Excel@, versão 2013 e posteriormente feita análise do discurso, conforme Bardin (2007, p 27) seguindo as etapas: Pré-análise: fase da organização dos dados, documentos, formulação de hipóteses; Exploração do material: momento da escolha de quais categorias, unidades de registros serão usados para codificar os dados obtidos, e Tratamento dos resultados: após a fase b, com os dados categorizados foram feitas as inferências e interpretações das mensagens e vocabulários observados no discurso dos entrevistados.

\section{RESULTADOS E DISCUSSÃO}

\subsection{RECORTE SOCIOECONÔMICO DOS AGRICULTORES ENTREVISTADOS}

Com a titulação de comunidade quilombola, o Mocambo pôde acessar seus direitos básicos, como energia elétrica (Luz para Todos), moradia (Programa Minha Casa Minha Vida), o Bolsa Família, a aposentadoria e a criação de escolas, prerrogativas para uma melhoria de vida. Apesar destes benefícios, a principal motivação da busca pelo título de reconhecimento de domínio coletivo foi a entrada de fazendeiros, seixeiras e indústrias de cerâmica na região. A partir de então, houve o incentivo à exploração ilegal de madeira e à comercialização de terras em área de várzea para retirada de barro. Nesse contexto, percebe-se o uso dos direitos 
constitucionais como amparo à luta e defesa do território como sendo o principal estímulo na busca pelo reconhecimento como remanescentes de Quilombo.

Os agricultores entrevistados encontram-se com média de 55 anos de idade, todos estão em uma união estável. A escolaridade é baixa, sendo um agricultor não alfabetizado, enquanto parte frequentou apenas quatro anos de vida escolar ( $4^{\mathrm{a}}$ série do ensino fundamental), e o restante aprendeu a ler e escrever por meio da educação à distância através da Radiofônica, programa de rádio que tinha como objetivo levar educação para as áreas de difícil acesso e que não possuíam escolas. Somente um dos entrevistados possui pós-graduação na área de educação.

Da amostra, todos residem há pelos menos 46 anos na comunidade. A economia local é essencialmente agrícola, movimentada principalmente pela renda obtida de aposentadorias, venda de farinha e da raiz de mandioca comercializadas para as farinheiras industriais e por seixeiras e indústrias de cerâmica que empregam alguns moradores. Assim, a renda média familiar dos agricultores chegou a aproximadamente dois salários mínimos.

Quanto à saúde, não há posto na comunidade, porém ocorrem consultas itinerantes, e nos casos mais graves os moradores se locomovem até a cidade de Ourém. Entre os entrevistados faz-se o uso de ervas medicinais, curandeiras, parteiras e benzedeiras, sendo uma prática comum em tempos passados. Hoje, com a introdução do neopentecostalismo evangélico, esses costumes vêm sendo discriminados fazendo com que sua reprodução seja reduzida, ou até mesmo evitada.

Nesse cenário foi observado um diálogo entre religiões de matriz africana e outros movimentos religiosos - principalmente a religião hegemônica no Brasil - o catolicismo. Da mesma forma que o constatado por De Carvalho (1999), esse sincretismo é a base das religiões de matriz africanas atualmente no Brasil. O catolicismo sempre acompanhou a história da comunidade, seguindo com a oração do terço e a coroação de Santa Maria. É a principal religião, onde pode-se encontrar em cada casa uma imagem de Nossa Senhora, ou de Jesus Cristo e diversos Santos e Santas (Figura 2). Esse grupo de pessoas criaram fortes laços ao longo do tempo. É nas proximidades da igreja que se desenvolve a comunidade, lá mulheres e homens se reúnem para realizar atividades e trocar experiências de vida.

Figura 2 - Imagens religiosas encontrada nas casas das famílias entrevistadas

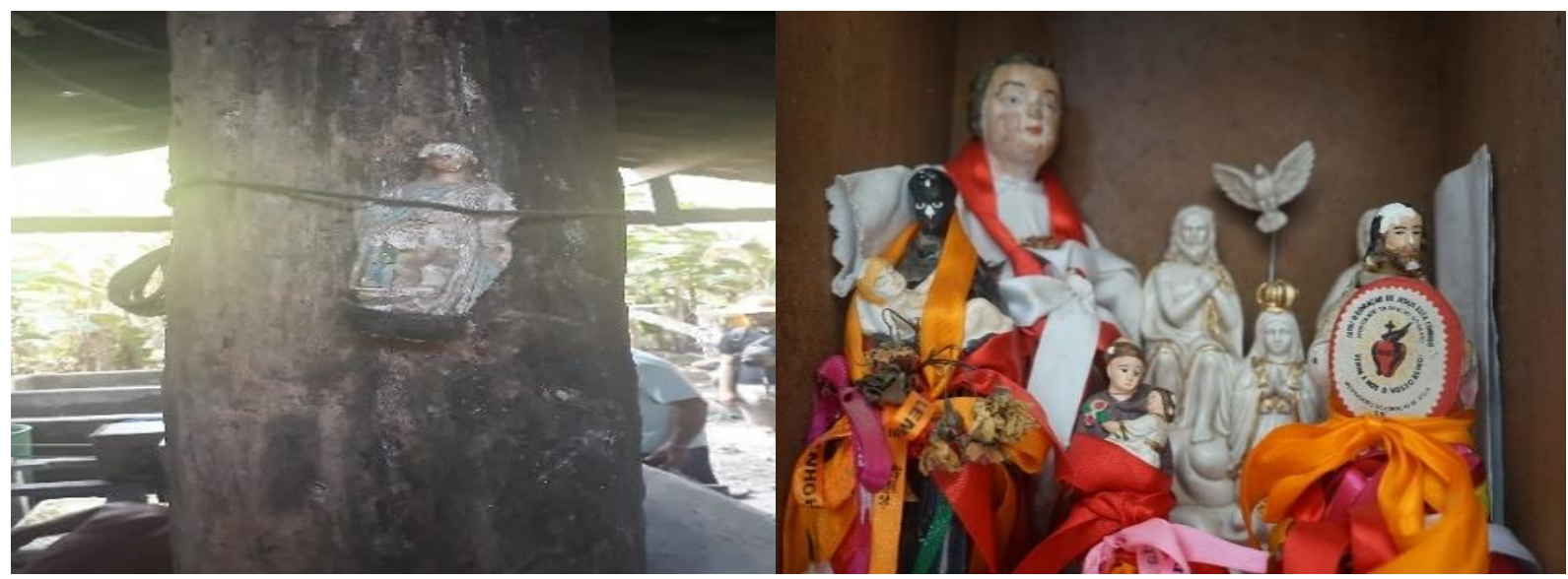

Fonte: Dados da pesquisa de campo, 2019. 
O Mocambo possui uma cultura bem marcante. A Ciramba ${ }^{7}$ é a principal atividade cultural e de entretenimento local. O Círio de Nossa Senhora Santa Maria é a principal festa religiosa da comunidade. O cortejo parte da comunidade do Cafeteua chegando à igreja que leva o mesmo nome da santa. No caminho, a imagem e seus peregrinos recebem várias homenagens dos fiéis (Figura 3).

Figura 3 - Círio de Nossa Senhora Santa Maria organizado pelos moradores

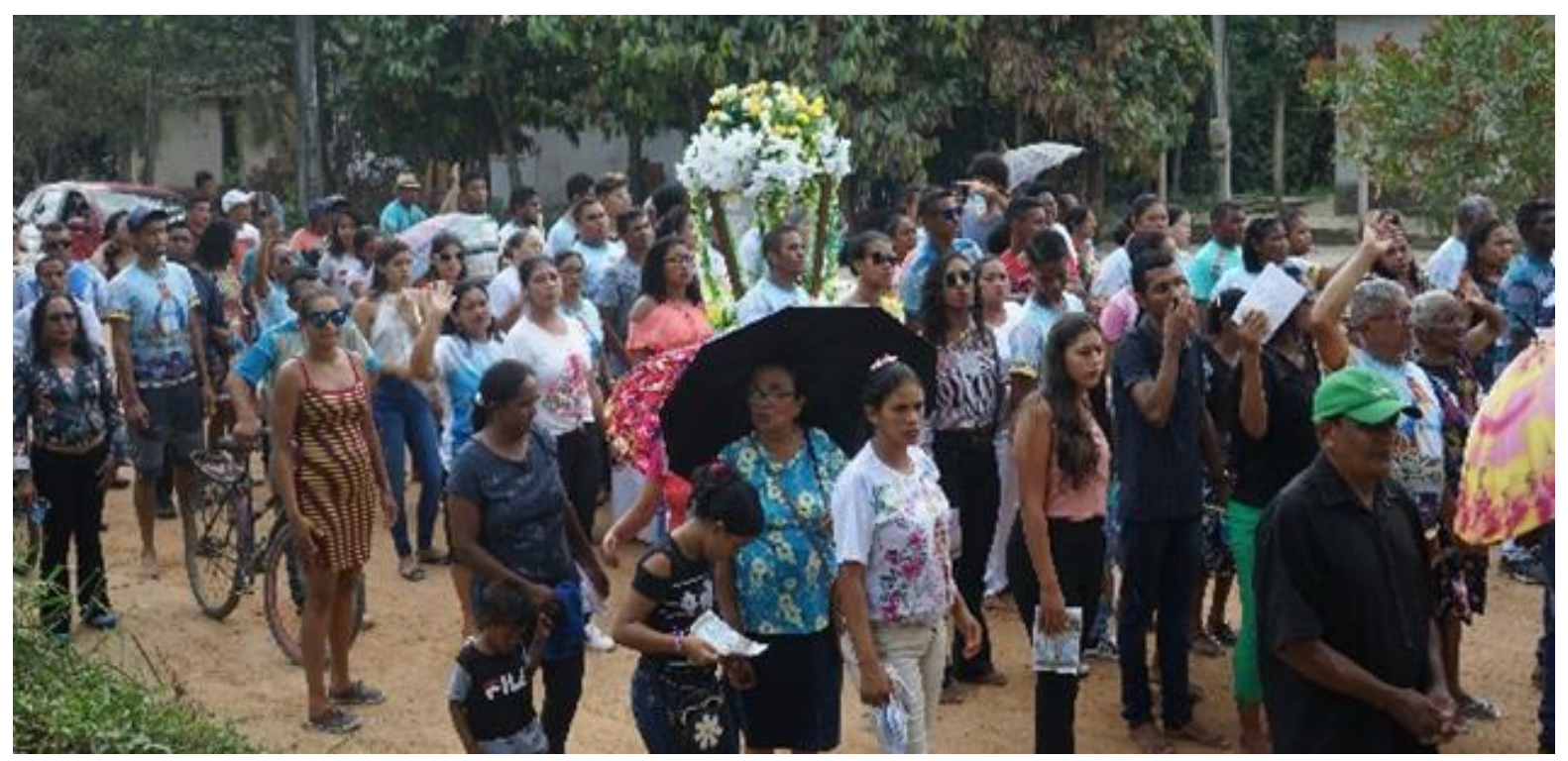

Fonte: Dados da pesquisa de campo, 2019.

Segundo relatos do presidente da associação, sr. José Maria dos Santos Farias, estruturalmente a comunidade conta com uma escola de ensino fundamental, uma igreja católica, duas igrejas neopentecostais evangélicas e um prédio de um pavimento utilizado para reuniões da associação comunitária agrícola e associação de mulheres (Figura 4: a) Escola de ensino Fundamental; b) Prédio de reuniões da associação comunitária agrícola e associação de mulheres e c) Igreja Católica, respectivamente). Conta também com a presença de um campo de futebol.

Figura 4 - Algumas estruturas da comunidade do Mocambo

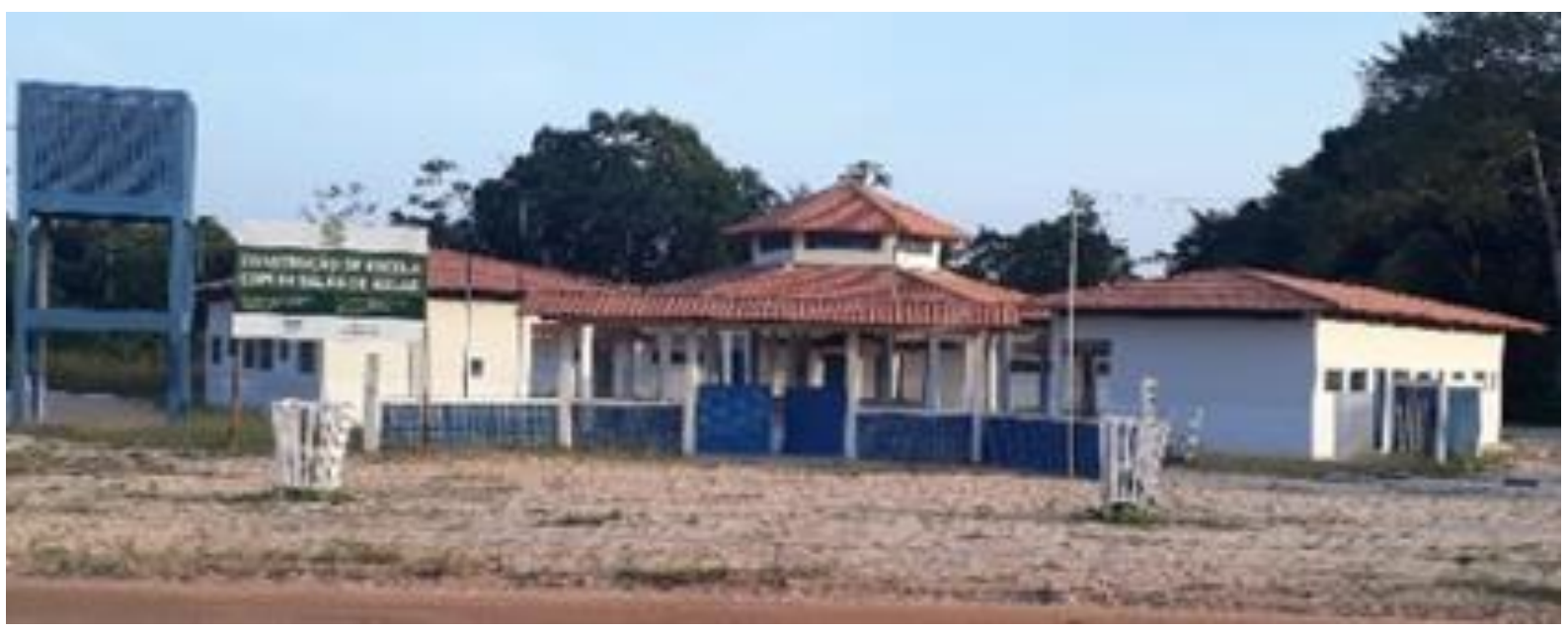

${ }^{7}$ Dança típica da comunidade do Mocambo onde homens, mulheres e crianças dançam entoando cantigas mostrando acontecimentos do dia a dia. 
Fonte: Dados da pesquisa de campo, 2019.

Figura 5 - Algumas estruturas da comunidade do Mocambo
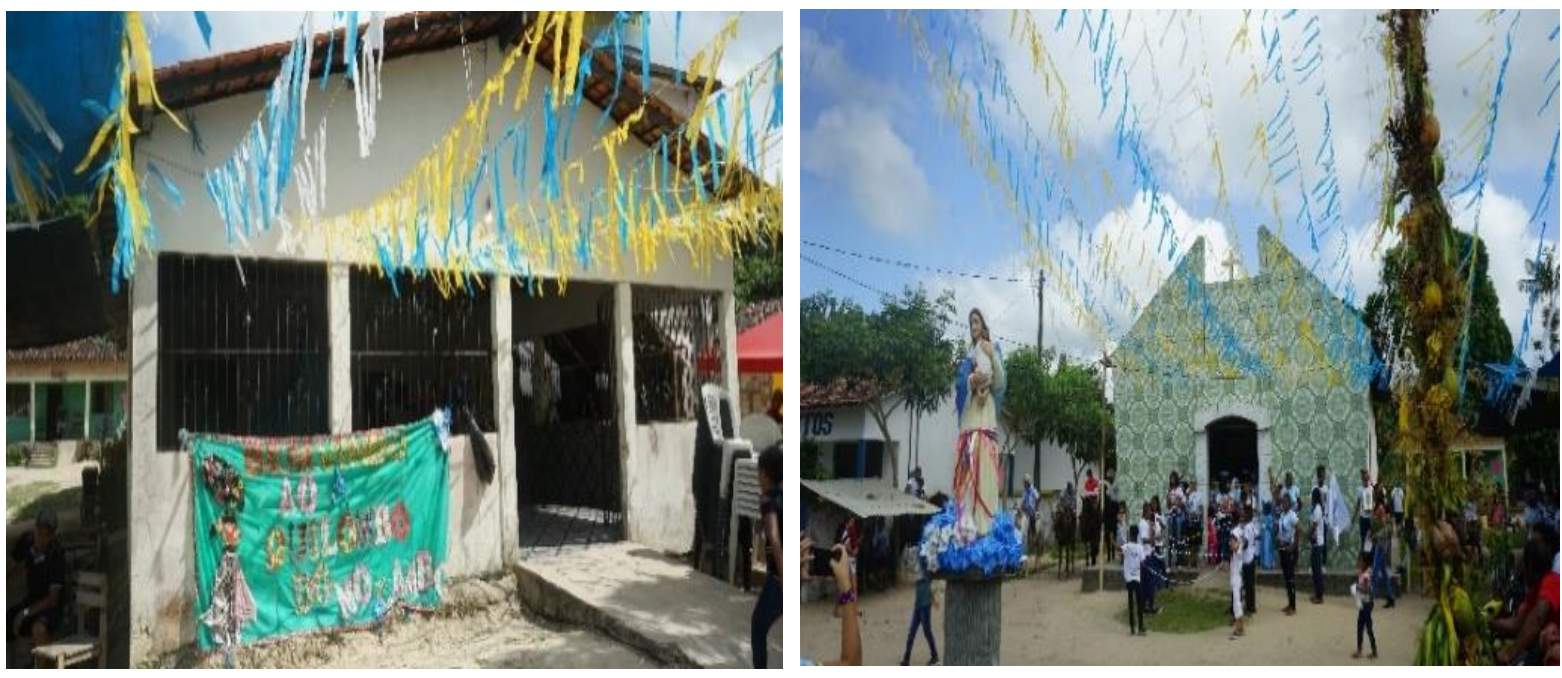

Fonte: Dados da pesquisa de campo, 2019.

O acesso ao Mocambo se dá através da PA 251, estrada não asfaltada e sem infraestrutura padronizada, como sinalização ou quebra-molas. O intenso trânsito de caminhões e caçambas transportando seixo e barro acaba por mover partículas de solo no ar causando problemas respiratórios em crianças e idosos. Após diversos conflitos, a comunidade entrou em acordo com as empresas, então ficou estabelecido algumas horas do dia (das 13 às 15 horas) para que seja feito o umedecimento do solo por meio de um caminhão pipa (Figura 5). A estratégia vem sendo respeitada, porém, com pouca eficiência, já que até hoje as casas fecham suas portas e janelas durante todo o dia para evitar a entrada da poeira.

Figura 6 - Caminhão pipa molhando a estrada principal (PA 251) na comunidade do Mocambo

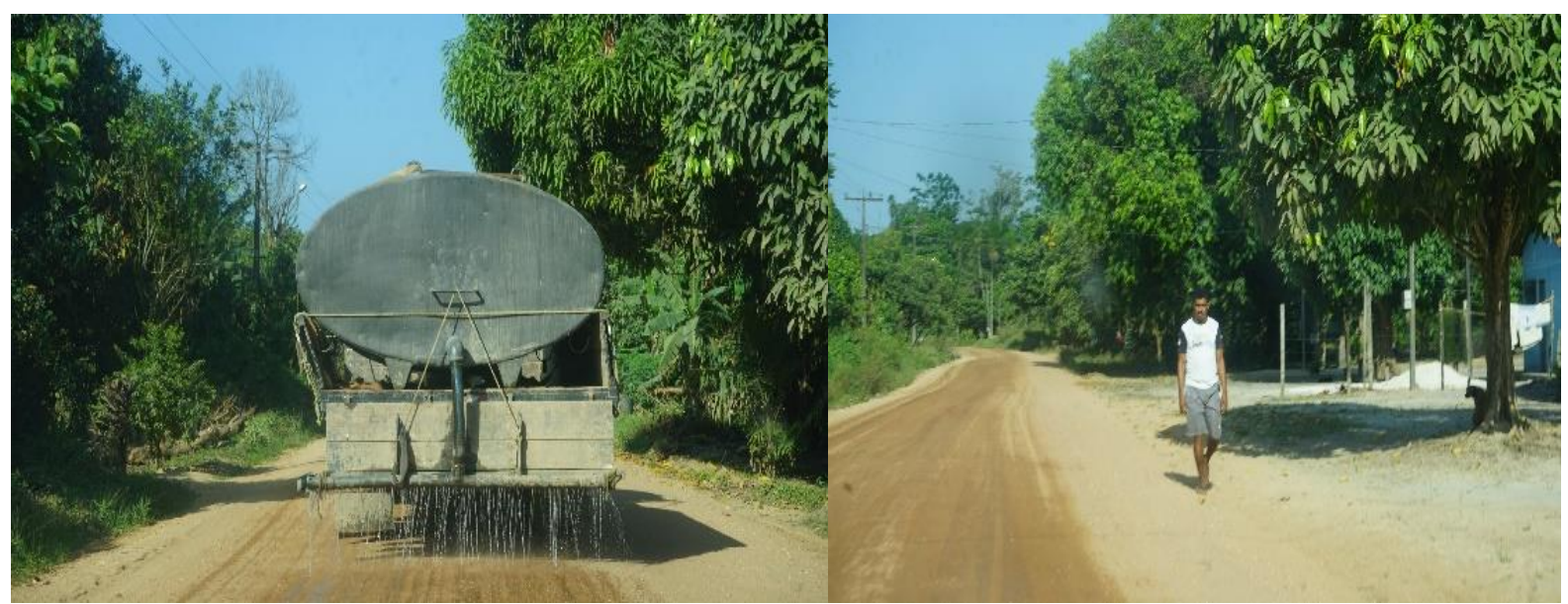

Fonte: Dados da pesquisa de campo, 2019.

Mudanças ambientais têm sido percebidas pela população, sendo evidenciada através da diminuição ou sumiço dos igarapés às proximidades da comunidade. Isto pode estar ligado ao desmatamento das florestas próximas e a retirada do barro das bordas das nascentes. 
O Mocambo, assim como muitas comunidades tradicionais, sofre o impacto da presença de grandes empreendimentos. No caso da comunidade em questão, os principais atores são as seixeiras, os fazendeiros, as indústrias de cerâmica e as farinheiras industriais, que juntos têm a capacidade de modificar toda a estrutura social da comunidade. As influências passam por várias nuances, como o modo de produzir a farinha, por exemplo, que segundo relatos dos agricultores, há agora a opção de vender a mandioca em tonelada de raiz, sem ter a obrigação de produzir a farinha. Por outro lado, os preços são controlados pelas farinheiras e normalmente são abaixo dos preços de mercado. Além de outras intervenções que serão vistas a seguir.

\subsection{A PRODUÇÃO DA FARINHA DE MANDIOCA}

A mandioca produzida na comunidade é plantada na roça, distante das residências cerca de 4 a 6 quilômetros cujo tamanho varia entre 2 a 6 tarefas $^{8}$. As casas de farinha comumente se localizam as proximidades das moradias, mais precisamente no quintal. A estrutura é composta por um barracão, feito de pau-a-pique, um forno, já relativamente padronizado, um ou mais cochos feitos de madeira ou cimento, e diversas ferramentas, instrumentos e recipientes adequados para fazer a farinha, sendo a maioria confeccionados artesanalmente pelos agricultores (Figura 6).

Figura 7 - Algumas estruturas da casa de farinha na comunidade do Mocambo

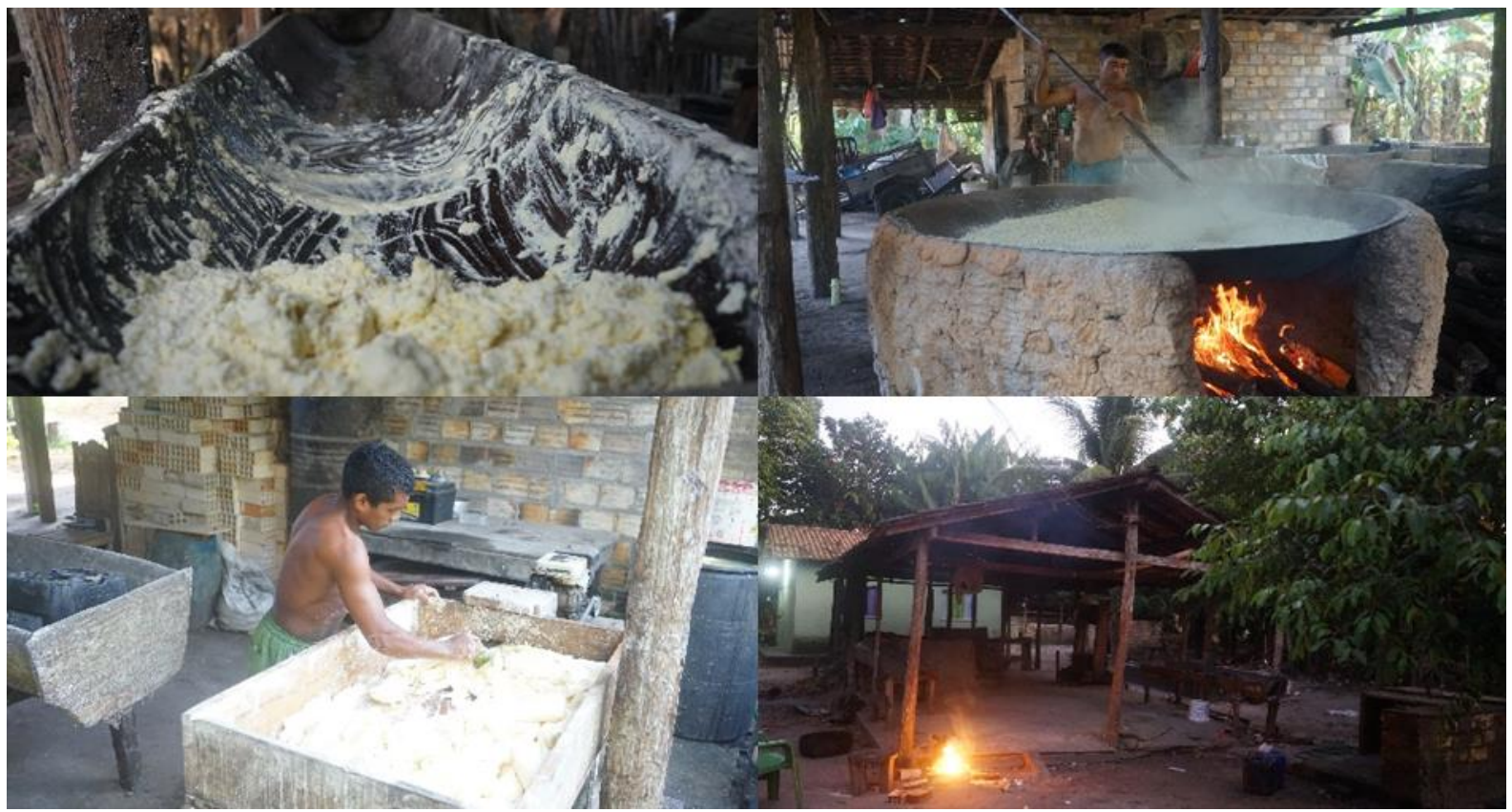

Fonte: Dados da pesquisa de campo, 2019.

As casas de farinha são artesanais, e assim como as roças, são de propriedade individual, porém, estas são utilizadas de forma coletiva, sendo frequentadas por parentes e vizinhos. A produção de farinha é direcionada principalmente ao autoconsumo, pois, os agricultores produzem em ritmo reduzido, devido principalmente a outras formas de renda, como a aposentadoria e o Bolsa Família. Também se atribui a baixa produtividade à idade avançada dos agricultores, à comercialização em raiz e à utilização de baixa tecnologia.

A comercialização da farinha in natura é feita esporadicamente e/ou quando há excesso de produção ou necessidade econômica. Em outras palavras, os agricultores não produzem com

${ }^{8} 1$ tarefa equivale a 0,3 hectares. 
objetivos mercadológicos, mas direcionados principalmente ao autoconsumo. A venda da farinha e da raiz de mandioca acontece para os atravessadores, que revendem em Belém, Castanhal, e Ourém, ou feita diretamente nas fábricas de farinha industrial localizada as proximidades. Os agricultores entrevistados utilizam a troca entre si. A venda entre vizinhos, acontece de forma esporádica.

Conforme as entrevistas, a produção de farinha é tida como fundamental para a reprodução da família, pois não só garante a segurança alimentar, como também contribui com uma renda extra, além de reviver memórias de convivência com seus antepassados, já que os agricultores assimilaram conhecimentos a respeito dos processos de produção da farinha com os avós, pais, mães e tios.

Seguindo as práticas antigas, ainda hoje, crianças, adolescentes, homens e mulheres se envolvem na produção da farinha. A diferença é que a mulher era a responsável por grande parte do trabalho, inclusive a torragem da farinha. Atualmente, o homem se estabeleceu neste papel, mas a mulher continua a contribuir com seu trabalho em diversas etapas do processo produtivo. Por outro lado, os jovens se interessam cada vez menos pela atividade agrícola, o que pode pôr em risco sua continuidade dentro do processo sucessório.

Os produtores de farinha utilizam alguns critérios para escolha do melhor período para o plantio. Segundo as informações coletadas em campo, eles plantam mandioca duas vezes ao ano, o plantio de inverno (janeiro a março) que eles chamam de "plantio no tempo" e o plantio de verão (julho a setembro). O cultivo é orientado pelo ciclo lunar, especialmente lua crescente e lua cheia, que, segundo os agricultores, são as melhores fases para o plantio.

Além da mandioca, os agricultores cultivam diversas hortaliças, como o milho, o arroz, e algumas frutas, além de espécies madeireiras e plantas medicinais. Cada variedade de mandioca plantada tem um período de colheita que varia de seis meses a um ano, assim os agricultores têm produção dispersa ao longo do tempo, garantindo a segurança alimentar de suas famílias.

Outro aspecto importante é a tradição em plantar as variedades de mandioca na estação chuvosa, ou "plantio no tempo" que segundo Otsubo e Lorenzi (2002), é a época em que o clima está mais quente e úmido, sendo o mais propício para brotação e enraizamento das estacas.

Pesquisas realizadas por Oler e Amorozo, 2017; Peroni; Hanazaki, 2002; Peroni, 2004 mostraram grande riqueza de variedades de mandioca cultivadas em diversas comunidades, diferente do ocorrido no Mocambo. Atualmente os agricultores cultivam principalmente as variedades de mandioca Cearense e Arruda, por suas características, como coloração do caule e raiz, de maior produtividade e mais atrativas na hora da comercialização.

As informações coletadas indicam a importância do encontro entre os saberes locais com os conhecimentos gerados através de instituições científicas, ou de cunho desenvolvimentista, onde a partir daí ocorrem adaptações, ou mudanças nas práticas agrícolas vivenciadas na comunidade ao longo do tempo. Na Tabela 1 é possível observar as mudanças na escolha das variedades utilizadas na produção da farinha.

A baixa diversidade varietal demonstrada pode ser resultado da influência das farinheiras próximas que possuem um padrão de produto, e, portanto, selecionam os fornecedores forçando sua adequação a estes padrões. No passado existiam pelo menos oito variedades (Tabela 1) que deixaram de ser produzido, o que pode causar perdas irreversíveis para a biodiversidade da mandioca local (OLER; AMOROZO, 2017).

O itinerário técnico apresentou transformações (Tabela 1), e observou redução no esforço laboral dos agricultores, pois, a partir de então, houve parcial substituição dos artefatos manuais por máquinas elétricas ou mecânicas. Apesar das modificações ocorridas, os entrevistados ainda conseguem manter alguns conhecimentos locais. As mudanças ocorridas são impulsionadas pela pressão exercida pelo mercado consumidor, porém, grande parte dos 
relatos mostraram que a produção é conduzida principalmente para o autoconsumo podendo esta ser uma forma de manter os saberes locais resistentes.

Tabela 1 - Itinerário técnico da roça de mandioca: Continuidades e mudanças

\begin{tabular}{|c|c|c|}
\hline & Antes & Atual \\
\hline Colheita & Manual & Manual, mecanizada \\
\hline Variedades & $\begin{array}{l}\text { Arruda, Branca Ouro, Cearense, } \\
\text { Arruda, Amarela, Caranã, Xibuí, } \\
\text { Milagrosa, Pecuí e Pretinha }\end{array}$ & Cearense e Arruda \\
\hline Limpeza & Descasca manual com a faca & Descasca manual com a faca \\
\hline Ralagem & $\begin{array}{l}\text { Ralador manual, ralador com } \\
\text { pedal e ralador a manivela }\end{array}$ & $\begin{array}{c}\text { Ralador elétrico (Caititu), ralador } \\
\text { manual, ralador com pedal e } \\
\text { ralador a manivela }\end{array}$ \\
\hline Pubagem & Feita no Rio & $\begin{array}{l}\text { Feita em tanques de cimento ou } \\
\text { camburões de plástico }\end{array}$ \\
\hline Prensa & Tipiti $^{9}$ & Tipiti e prensa hidráulica \\
\hline Desintegração da massa & Crivo manual & Crivo manual \\
\hline Transporte & Jumento e barco & $\begin{array}{c}\text { Jumento, barco e carreta acoplada } \\
\text { a moto }\end{array}$ \\
\hline Adubos & Não era utilizado & NPK \\
\hline Preparo de área & $\begin{array}{c}\text { Derrubada e queima, machado, } \\
\text { terçado, enxada }\end{array}$ & $\begin{array}{l}\text { Derrubada, queima, gradagem, } \\
\text { motosserra, terçado, enxada }\end{array}$ \\
\hline $\begin{array}{l}\text { Ferramentas p/ produção da } \\
\text { farinha }\end{array}$ & $\begin{array}{l}\text { Rodo de madeira, cocho, forno a } \\
\text { lenha }\end{array}$ & $\begin{array}{c}\text { Rodo de madeira, cocho, forno a } \\
\text { lenha }\end{array}$ \\
\hline Organização social do trabalho & Meia, troca de dias e diária & Troca de dias e diária \\
\hline
\end{tabular}

Fonte: Dados da pesquisa de campo, 2019.

Práticas como a pubagem são bem comuns na escala produtiva da mandioca. A pubagem, segundo os agricultores, é a prática onde se coloca a mandioca descascada em sacas dentro do rio, ou em recipientes feitos de cimento ou de plástico cheios de água. Então, a mandioca fica quatro dias de molho para depois ser prensada e torrada, lhe conferindo assim um diferencial da farinha produzida de forma industrial. Conforme relato do entrevistado A da comunidade do Mocambo: "A farinha fica boa, diferente da feita na farinheira grande que eles num deixa de molho e a farinha fica azeda" (Entrevistado A, Mocambo, 2019).

Esta técnica está deixando de ser realizada no rio por conta de os agricultores terem observado mudanças no cheiro e coloração da água. As entrevistas mostraram preocupação por parte dos agricultores em relação às mudanças ambientais, sejam relacionadas a água, solo, clima e/ou vegetação. Estas transformações e as influências externas influenciam seu modo de vida, como ocorre com a produção de farinha e seus derivados.

A Tabela 1 mostra que os produtores utilizam adubo, principalmente após a gradagem realizada com maquinário da prefeitura. E na perspectiva do entrevistado B: "A terra fica fraca com o tempo depois que passa a máquina. Então, a gente põe o adubo. Na terra de toco não precisa" (Entrevistado B, mocambo, 2019).

Essa fala mostra a percepção dos agricultores em relação à mudança na estrutura do solo após a gradagem. A utilização de maquinários agrícolas surgiu com objetivo de tornar o agricultor mais produtivo, no espaço e tempo, porém, estes reconhecem que ao longo do tempo é mais difícil produzir em um solo em que sua estrutura tenha sido modificada. Nestes casos,

\footnotetext{
${ }^{9}$ O tipiti é uma espécie de espremedor de palha trançada, usado para escorrer a massa da mandioca passada no caititu (SANTANA, 2018, p. 53).
} 
segundo o entrevistado B: "[...] a terra mexida só tem produção se tiver adubo" (Entrevistado B, Mocambo, 2019).

Alguns dos produtores entrevistados, seguindo as práticas passadas de geração em geração, não utilizavam adubo químico e preferem não fazer a gradagem. Baseado nos dados é possível dizer que estes não dependem da comercialização da mandioca ou da farinha para sua sobrevivência, pois já possuem outras formas de renda, como a aposentadoria. É o caso do entrevistado C, como mostra o relato: "Plantava muita maniva, hoje não planto mais. Já tô velho, só planto para comer. Venda só às vezes, em caso de necessidade ou para comer. Depois que aposentei, eu e a mulher agente só planta por costume" (Entrevistado C, Mocambo, 2019).

A organização social do trabalho, conforme a Tabela 1, acontece em torno da reciprocidade e ação coletiva (MAUSS, 2011). Na época de queima, preparo da terra, plantio, colheita e/ou produção de farinha, os agricultores "trocam dia". Essa prática acontece quando um agricultor ajuda o outro, e em troca, este terá como dívida moral apoiá-lo quando necessário nas atividades agrícolas, ou seja, eles trocam dias de trabalho. Não existe necessariamente uma relação de troca mercantil, com remuneração em dinheiro. Pelo observado, é uma prática bastante aceita na comunidade. Porém, conforme relatos dos agricultores, essa relação mútua está deixando de ser praticada dando espaço a contratação de mão de obra.

É importante enfatizar algumas diferenças encontradas entre os entrevistados que vivem na Vila Beira Rio (as margens do Rio Guamá) e os entrevistados moradores e/ou próximos da avenida principal (PA 251). Os agricultores da Vila utilizam estratégias rústicas de produção da farinha. Utilizam principalmente o ralador com pedal a manivela e o tipiti e não utilizam defensivos ou adubos químicos conforme a Tabela 1.

Isso pode ser resultado do pouco contato com as farinheiras industriais, diferente do que acontece com alguns agricultores do "centro" da comunidade. Estes já estão investindo em maquinários para produção da farinha, compra de adubo, negociam a farinha e/ou a raiz, e possuem as melhores e mais bem localizadas terras para o plantio.

Dessa forma os moradores da Beira Rio possuem pouco poder de negociação, ficando ao ritmo de produzir para subsistência, e quando possível, fazer a comercialização. Segundo o entrevistado D, morador da Vila: "Para essas banda, nós faz igual ao que aprendeu com os tio, e outros, continua tudo igual, mesmo com a chegada da farinheira grande e da energia" (Entrevistado D, Mocambo, 2019).

O trecho mostra que, principalmente nesta parte do Mocambo, os agricultores usam estratégias de manutenção dos costumes de plantar, colher e consumir/comercializar a farinha, reproduzindo o feito por seus antepassados. Os produtores próximos à avenida principal também mantêm a maioria das práticas produtivas utilizadas no passado, porém são favoráveis as mudanças e/ou adaptações com objetivo de acompanhar as exigências do mercado da farinha industrial.

Essa propensão dos agricultores do "centro" da comunidade pode ser reflexo da facilidade de acesso às informações, como por exemplo, consulta ao edital de chamada para fornecedor do Programa de Aquisição de Alimentos (P.A.A.) do governo federal e financiamento para maquinários agrícolas.

\section{CONSIDERAÇÕES FINAIS}

Esta pesquisa qualitativa teve como objetivo investigar, através de entrevistas com oito agricultores e agricultoras do Quilombo do Mocambo, Estado do Pará, quais fatores influenciaram as possíveis mudanças nas práticas produtivas da mandioca. Os resultados indicaram que a comunidade do Mocambo sofre forte influência de aspectos mercadológicos, novas tecnologias e a falta de sucessores no âmbito da produção de farinha de mandioca. A presença de farinheiras industriais próximas a comunidade aumentou ainda mais a pressão por 
adaptação às exigências do mercado. Essas mudanças ocorreram principalmente na escolha das variedades para o plantio, que foram reduzidas, fragilizando a biodiversidade local.

O itinerário técnico indicou algumas mudanças na produção, sejam elas por proximidade às indústrias de farinha, por facilidade de acesso às informações, acesso à energia elétrica, ou simplesmente por incorporação às novas tecnologias. Houve diferença entre os agricultores da Vila Beira Rio e os da PA 251, onde estes já investem em uma produção voltada para o mercado.

Os agricultores do Mocambo produzem e/ou participam da produção da farinha de mandioca desde tenra infância. Essa atividade faz parte de suas histórias e relações socioeconômicas. Apesar da pressão de mudança, ainda conseguem produzir combinando costumes e saberes intergeracionais às novas tecnologias. Essa forma de trabalhar garante, em parte, a continuação dos costumes tradicionais. Assim como permite adaptações em relação às novas tecnologias contribuindo com o incremento da produtividade para uma maior inserção no mercado local. Desta forma, os agricultores podem inclusive negociar a produção diretamente com os compradores. Os agricultores respeitam e sabem o que pode continuar sendo utilizado, assim como entendem a importância de aperfeiçoar as técnicas com a finalidade de melhoria de suas condições produtivas de trabalho.

Assim, sugere-se políticas públicas de incentivo à produção e difusão de novas tecnologias que respeitem as tradições e que ao mesmo tempo deem qualidade e produtividade para que o agricultor se torne competitivo. Ações que contribuam para a fixação do jovem na comunidade, como empoderamento e renda certa podem gerar um cenário de continuidade para a agricultura local.

Pesquisas no âmbito da sucessão familiar e produção de outras culturas agrícolas podem ser articuladas futuramente. Assim como analisar o acesso dos agriculturores(as) aos programas governamentais, como PAA, Minha Casa Minha Vida e outros na comunidade.

\section{AGRADECIMENTOS}

À Comunidade do Mocambo, Ourém - PA pela disponibilidade de tempo e abertura para esta pesquisa.

À Universidade Federal do Pará, pelo apoio.

\section{REFERÊNCIAS}

AGUIAR, P. Mandioca: pão do Brasil. Rio de Janeiro: Civilização Brasileira, 1982.

ALLEM, A. C. The origins and taxonomy of cassava. In: Hillocks, R. J.; Thresh, J. M.; Bellotti, A. (Eds.). Cassava: biology, production and utilization. Wallingford: CABI Publications, p. 1-16, 2002.

ANDRÉ, M. Etnografia da prática escolar. São Paulo: Papirus, 2005.

ANJOS, R. S. A; CYPRIANO, A. Quilombolas - tradições e cultura da resistência. Aori Comunicações. São Paulo: Petrobras, 2006.

ARRUTI, J. M. Quilombos. Revista Jangwa Pana, 8.1: 102-121, 2009.

BARDIN, L. Análise de conteúdo. (L. A. Reto \& A. Pinheiro, Trans.) ( $3^{\circ}$ ed.). Lisboa:

Editora 70, 2004. 
BRASIL. Decreto $n^{\circ}$ 4.887, de 20 de novembro de 2003. Regulamenta o procedimento para identificação, reconhecimento, delimitação, demarcação e titulação das terras ocupadas por remanescentes das comunidades dos quilombos de que trata o art. 68 do Ato das Disposições Constitucionais Transitórias.

BRASIL. Decreto $\mathbf{n}^{\mathbf{0}}$ 6.040, de 7 de fevereiro de 2007. Institui a Política Nacional de Desenvolvimento Sustentável dos Povos e Comunidades Tradicionais. Brasília, 7 de fevereiro de 2007.

CONAB. Companhia Nacional de Abastecimento. Disponível em: https://www.conab.gov.br/. Acesso em: 07 jul. 2021.

CHIZZOTTI, A. Pesquisa em ciências humanas e sociais. São Paulo: Cortez, 1991.

DA SILVA, G. S.; DA SILVA, V. J. Quilombos Brasileiros: alguns aspectos da trajetória do negro no Brasil. Revista Mosaico-Revista de História, v. 7, n. 2, p. 191-200, 2015.

De CARVALHO, J. J. Um espaço público encantado: Pluralidade religiosa e modernidade no Brasil. Universidade de Brasília: Departamento de Antropologia, 1999.

EMBRAPA. Empresa Brasileira de Pesquisa Agropecuária. Sistema de Produção de Mandioca no Semiárido, 2021. Disponível em: file:///C:/Users/Josi/Downloads/Sistema-deProducao-de-Mandioca-no-Semiarido.pdf. Acesso em: 02 maio 2020.

FRASER, J. A.; CLEMENT, C. R. Dark Earths and manioc cultivation in Central Amazonia: a window on pre-Columbian agricultural systems?. Boletim do Museu Paraense Emílio Goeldi. Ciências Humanas, v. 3, n. 2, p. 175-194, 2008.

FUNDAÇÃO CULTURAL PALMARES. Certificação Quilombola. Disponível em: http://www.palmares.gov.br/wp-content/uploads/2015/07/quadro-geral-por-estados-e-regioes15-06-2021.pdf. Acesso em: 04 jul. 2021.

FUNARI, P. P. A. A arqueologia de Palmares - Sua contribuição para o conhecimento da história da cultura afro-americana. In: REIS, J. J.; GOMES, F. dos (Org.). Liberdade por um fio: história dos quilombos no Brasil. São Paulo: Companhia das Letras, 1996.

IBGE. Instituto Brasileiro de Geografia e Estatística. Disponível em: https://www.ibge.gov.br/. Acesso em: 06 dez. 2019.

ITERPA. Institutos de Terra do Pará. Disponível em: http://www.iterpa.pa.gov.br/content/quilombolas. Acesso em: 02 jun. 2020.

LOBO, I. D.; DOS SANTOS JÚNIOR, C. F.; NUNES, A. Importância socioeconômica da mandioca (Manihot esculenta crantz) para a comunidade de Jaçapetuba, município de Cametá/PA. Multitemas, v. 23, n. 55, p. 195-211, 2018.

MAGNANI, J. G. C. O velho e bom caderno de campo. Revista Sexta-Feira, v. 1, n. 1, p. 812, 1997.

MAUSS, M. Sociologia e Antropologia. 4a ed. São Paulo: Cosac Naify, 2011. 
OLER, J. R. L.; AMOROZO, M. C. M. Etnobotânica e conservação on farm de mandioca (Manihot esculenta Crantz) na agricultura de pequena escala no Estado de Mato Grosso, Brasil. Interações, Campo Grande, v. 18, n. 4, p. 137-153, 2017.

ORGANIZAÇÃO DAS NAÇÕES UNIDAS PARA ALIMENTAÇÃO E AGRICULTURA FAO. Food Outlook - BIANNUAL REPORT ON GLOBAL FOOD MARKETS, 2017. Disponível em: http://www.fao.org/3/a-I8080e.pdf. Acesso em: 14 de nov. 2019.

OTSUBO, A. A.; LORENZI, J. O. Cultivo da mandioca na região Centro-Sul do Brasil. Embrapa Agropecuária Oeste-Sistema de Produção (INFOTECA-E), 2004.

PASA, M. C.; ÁVILA, G. Ribeirinhos e recursos vegetais: a etnobotânica em Rondonópolis, Mato Grosso, Brasil. Interações, Campo Grande, v. 11, n. 2, p. 195-204, 2010.

PERONI, N. Ecologia e genérica da mandioca na agricultura itinerante do litoral sul paulista: uma análise espacial e temporal. 2004. 227p. Tese (Doutorado em Biologia Vegetal) - Instituto de Biologia, Universidade Estadual de Campinas (UNICAMP), Campinas, SP, 2004.

PERONI, N.; HANAZAKI, N. Current and lost diversity of cultivated varieti es, especially cassava, under swidden cultivation systems in the Brazilian Atlantic Forest. Agriculture, Ecosystems and Environment, v. 92, n. 2-3, p. 171-83, 2002.

PIPERNO, D. R. The origins of plant cultivation and domestication in the New World Tropics: patterns, process, and new developments. Current Anthropology, v. 52, n. S4, p. 453-470, 2011.

RAMOS, D. O quilombo e o sistema escravista em Minas Gerais no século XVIII. In: Reis, J. J.; Gomes, F. dos S. (Org.). Liberdade por um fio: história dos quilombos no Brasil. São Paulo: Companhia das Letras, 1996.

REIS, J. J.; DOS SANTOS GOMES, F. (Ed.). Liberdade por um fio: história dos quilombos no Brasil. São Paulo: Editora Companhia das Letras, 1996.

SANTANA, E. D. Z. F. A casa de farinha como território de aprendizagem e a farinhada como processo educativo: estudo de caso no Distrito Janarí, Goianésia do Pará/PA. 90 p. Dissertação (Mestrado) - Universidade de Brasília, 2018.

SCHAAL, B. A.; OLSEN, K. M.; CARVALHO, L. J. C. B. Evolution, domestication, and agrobiodiversity in the tropical crop cassava. In: Motley, T.; Zerega, N.; Cross, H. (Eds.). Darwin's harvest. New York: Columbia University Press. p. 269-284, 2006.

VAINFAS, R. Dicionário do Brasil Colonial. Rio de Janeiro: Objetiva LTDA, 2000. 